\title{
Institutional Barriers to Developing Community Indicators in New Zealand: A Preliminary Assessment
}

\author{
Commonwealth Journal of Local Governance \\ Issue 1: May 2008 \\ http://epress.lib.uts.edu.au/ojs/index.php/cjlg
}

\author{
Ali Memon \& Karen Johnston \\ Lincoln University
}

\begin{abstract}
There has been enormous activity in many countries and by international agencies during the last few decades to develop indicators to measure trends in different attributes of the environment, including indicators for community wellbeing and for sustainable development. Identifying appropriate indicators of economic, social, environmental, cultural and democratic progress across local government boundaries, as a basis for a strategy to enhance community governance, and as part of a national system of sustainability indicators, is a challenging task. An important dimension that is implicit rather than explicit in the current literature is the significance of institutional barriers to developing indicators. Informed by recent New Zealand experiences, our objective in this paper is to examine those institutional barriers within the context of achieving the wider objectives of the New Zealand Local Government Act 2002 to strengthen participatory democracy and community governance, and the 'whole-ofgovernment' sustainable development paradigm that underpins it. We argue that the significance of undertaking the task of indicator development in a collaborative and participatory as well as technically satisfactory manner should not be under-estimated.
\end{abstract}

Key words: indicators, community wellbeing, sustainable development, institutional barriers, community governance, New Zealand. 


\section{Introduction}

Many governments are striving to improve the way they measure progress and plan for change from an integrated participatory, 'whole-ofgovernment', and sustainable development perspective. Historically, interest in the development of indicators to measure wellbeing can be traced to philosophical debates about the nature of the 'good life', 'good society' and 'progress'. More recently, since the 1970s, there has been enormous activity in many countries and by international agencies to develop indicators to measure trends in different attributes of the environment for healthy cities and for sustainable development, including State of the Environment reporting as well as indicators for community wellbeing (Waring 1990; Meadows 1998; Salvaris 2000). ${ }^{1}$

Identifying appropriate indicators of economic, social, environmental, cultural and democratic progress across local government boundaries as a basis for a strategy to enhance community governance and as part of a national system of sustainability indicators is a challenging task requiring social-scientific and technical expertise. But indicator development is not just a technical exercise and it is imperative that indicators should also reflect the values of the diverse communities they serve. This is best achieved through a participatory indicator development process. These issues are well traversed in the recent literature on the broad theme of sustainability indicators (Eckerberg and Mineur 2003; Rydin, Holman and Wolff 2003; Phillips 2005; Blair and Murphy Greene 2006). However, an important dimension that is implicit rather than explicit in the current literature is the significance of institutional barriers to developing community indicators. ${ }^{2}$ Informed by recent New Zealand experience, our objective in this paper is to examine those institutional barriers within the context of achieving the wider objectives of the New Zealand Local Government Act 2002 (henceforth the LGA or the Act) to strengthen participatory democracy and community governance, and the whole-ofgovernment sustainable development paradigm that underpins it. We argue that the significance of undertaking the task of indicator development in a collaborative and participatory as well as technically satisfactory manner should not be under-estimated.

This paper is organised as follows. In Section 2, key institutional considerations pertinent to indicator development are reviewed to set the context. Next, Section 3 provides an overview of the current New Zealand

\footnotetext{
1 The term environment is used in this paper in a holistic sense inclusive of social, economic, ecological and good governance attributes.

${ }^{2}$ Community indicators measure broad trends in community outcomes and are different from programme evaluation and performance indicators which measure the effectiveness and efficiency of specific agency initiatives and programmes. In the New Zealand context, community indicators is a term for indicators that are developed at the local and regional scale through a process that has involved the community and inter-governmental collaboration, as explained in Section 3.
} 
institutional setting for community indicator development as a case study. The focus in Section 4 is on interrogating barriers to indicator development from two related perspectives: inter-governmental collaboration and local government interpretation of the indicator development mandate in the LGA. The study findings are discussed in Section 5, and Section 6 concludes.

\section{The Wider Context}

The analytical approach in this study draws on the institutional analysis research paradigm in recent policy and planning literatures. Recently, there has been a rapid rise in interest in institutional arrangements that underpin various aspects of our lives in economic, political and social spheres. The term 'institutional arrangements' is used broadly, inclusive of both the formal organisations of government and those informal mechanisms ie rules, mores, practices (or indeed the lack of them) that provide incentives and disincentives for actors to behave in particular ways. The core of the institutionalist perspective is the insight that formal organisational arrangements on their own do not provide an adequate explanation of dynamics and outcomes, and that informal organisational forms are equally significant (Rydin and Falleth 2006). All kinds of external influences affect the way in which individuals form their decision-making processes. Thus, it is how both the formal institutions ('hard infrastructure') and informal institutions ('soft infrastructure') shape the patterns of social interactions which produce social phenomena, and how those institutions emerge from such interactions that is of increasing concern (Hajer and Wagenaar 2003).

The formal and informal networks between actors help explain how governance processes work. Institutional capacities at the macro and micro level are set within time-place relations which are complex and everchanging. The shifting social context means that transformation processes are not static; too much emphasis on habitual practices and ways of doing things can stifle participants, whereas being open to others' views and being able to deliberate in network arrangements will allow trust in community governance to develop (Healey et al. 2002; Kothari 2001).

The literature on the nature, purpose and compilation of community indicators is now extensive and offers a valuable source of ideas and information for policy makers and practitioners to draw on (Waring 1990; Meadows 1998; Salvaris 2000; Hings and White 2000; Hoernig and Seasons 2005; VCIP 2005; Innes 1997; Blair and Murphy-Greene 2006). This literature provides potentially useful leads to interrogate institutional barriers manifest in emerging approaches to indicator development for monitoring and reporting progress towards desired community outcomes in New Zealand, as explained below. There are two basic criteria against which to examine emergent approaches towards indicator development: community involvement to develop meaningful indicators; and expert input to ensure that the content and calibre of indicators are technically sound. 


\section{Community involvement}

Community indicators are statistical tools for translating broad community goals into clear, tangible and commonly understood outcomes, and for assessing and communicating progress in achieving these goals and outcomes (VCIP 2005). Community indicators should represent open, value choices. They should be chosen not just for technical or statistical reasons, but also on the basis of the political and philosophical values of those who choose them. Thus, a community indicator suite should sit within a longterm vision for the community's future, and high levels of community and stakeholder involvement are essential to obtaining meaningful indicators to complement expert input.

Community indicators can also play an important role in mobilising citizens to set priorities and goals and to participate in community planning and problem-solving efforts. Strengthening citizen engagement in identifying community concerns and priorities is itself a key democratic objective in the development of community indicators. Developing community indicators enables participants to recognise shared goals and visions, and the limitations of conventional indicators such as GDP (Besleme and Mullin 1997). This means the choice of community indicators should be made as openly and democratically as possible (VCIP 2005). Community involvement in indicator development enhances their purposefulness dramatically. It helps build community awareness across many facets of society, brings wider acceptance and allows attention to be devoted to resolving difficult issues in the community.

Lack of stakeholder and wider community awareness and involvement in indicator construction is likely to mean that behaviour changes towards sustainability values will be more difficult to achieve. "Information does not influence unless it represents a socially constructed and shared understanding created in the community of policy actors" (Innes 1997, p. 56). An indicator development process also has an important communication function in social learning including educating, informing, and linking diverse communities. Again, an indicator suite constructed with minimal community input will have difficulty fulfilling this function.

For all the above reasons, it is imperative that institutional arrangements facilitate public engagement in the process of indicator development. The role of local government in western societies, including New Zealand, has changed significantly since the 1990 s in response to wide ranging trends including globalisation and economic competition, the progressive erosion of the role of the central state, international migration, and increasing social diversity. Today's local governments have more need than ever to understand and engage their communities in order to meet these challenges, and play a more direct role in community wellbeing. This can potentially form a foundation towards new models of local governance (Salvaris 2000). 


\section{Expert input}

Desirable technical attributes of indicators include plausible and measurable goals, targets and standards, and robustness. These are significantly dependent on appropriate institutional arrangements to facilitate collaborative input by central and local government officials and other experts. Input by such experts in indicator development should complement community and stakeholder participation to ensure that indicators are technically robust. It has been argued by some critics that attempts to determine just what sustainability is and how it will be achieved tend to be top-down and expert-led, with limited public input, a command-and-control orientation, and use of indicators "developed by scientists for scientists" (Bell and Morse 1999, p. 48). However, the role of central government expert input should not be negated; technical and professional people bring knowledge of social, economic and environmental issues, as well as knowledge of indicator principles and data availability.

Community wellbeing indicators should, as far as possible, be co-ordinated and complementary at local, regional and national levels (multi-scalar). There are real benefits and efficiencies - democratic, planning and policy when different levels of government and different governments within these levels have a common accountability framework and a common language for measuring progress. This applies both horizontally or spatially between districts and regions, and vertically from the national to the regional and local levels. A nationwide system of comparable community indicators based on each local government area can be used as a building block for wellbeing measurement at the national level within a broader sustainability context, and as a basis for central government department planning. A collaborative indicator development process also has considerable potential for coordinating the numerous central government and other agencies working on environmental, social, economic, human health and natural resource problems within a local authority area. It will be difficult to capitalize on this function if central government officials have little awareness of, or stake in, the indicator development process.

Co-ordination offers a number other advantages as well:

- Consistent measurement with the ability to map trends at city, district, regional and national levels to chart progress towards desired outcomes;

- Alignment of national monitoring initiatives with sectoral (departmental) and regional and local indicators (whole-ofgovernment approach to monitoring);

- Cost savings and efficiencies associated with joint data purchasing, collection and dissemination;

- Benefits associated with building on the experience gained through existing monitoring initiatives (including support in the selection of robust indicator measures and the ability to tap into existing monitoring systems); and 
- Opportunities for joint consultation with feedback from and collaboration with data providers around the core indicator set.

To sum up, the challenge in designing community indicators is to successfully integrate a broad community based 'bottom-up' approach to indicator development with a central and local government expert-driven methodology. Thus, the task of indicator development is akin to marrying government with governance rather than signifying a shift from government to governance. ${ }^{3}$ This emphasises the significance of a collaborative strategy for indicator development.

Based on the above literature review, we adapted a schematic model for developing community outcomes proposed by Blair and Murphy-Greene (2006) to steer our interrogation of how New Zealand local authorities have developed their community indicator programmes in a collaborative fashion (Figure 1 below). Expert guidance by central and local government officials and other experts during the construction of the process and at the end of each major iteration in the process, as suggested in Figure 1, is recommended. Blending the public's views with technical input in this way helps to bring about a set of realistic and technically robust community indicators that are supported by the wider community.

\footnotetext{
${ }^{3}$ While 'government' reflects a hierarchical 'top-down' form of policy-making, more recent forms of spatial 'governance' utilize local partnerships, networks and collaboration between civil society, private sector and government.
} 


\section{Schematic Process Model for Developing Community Indicators ${ }^{4}$}

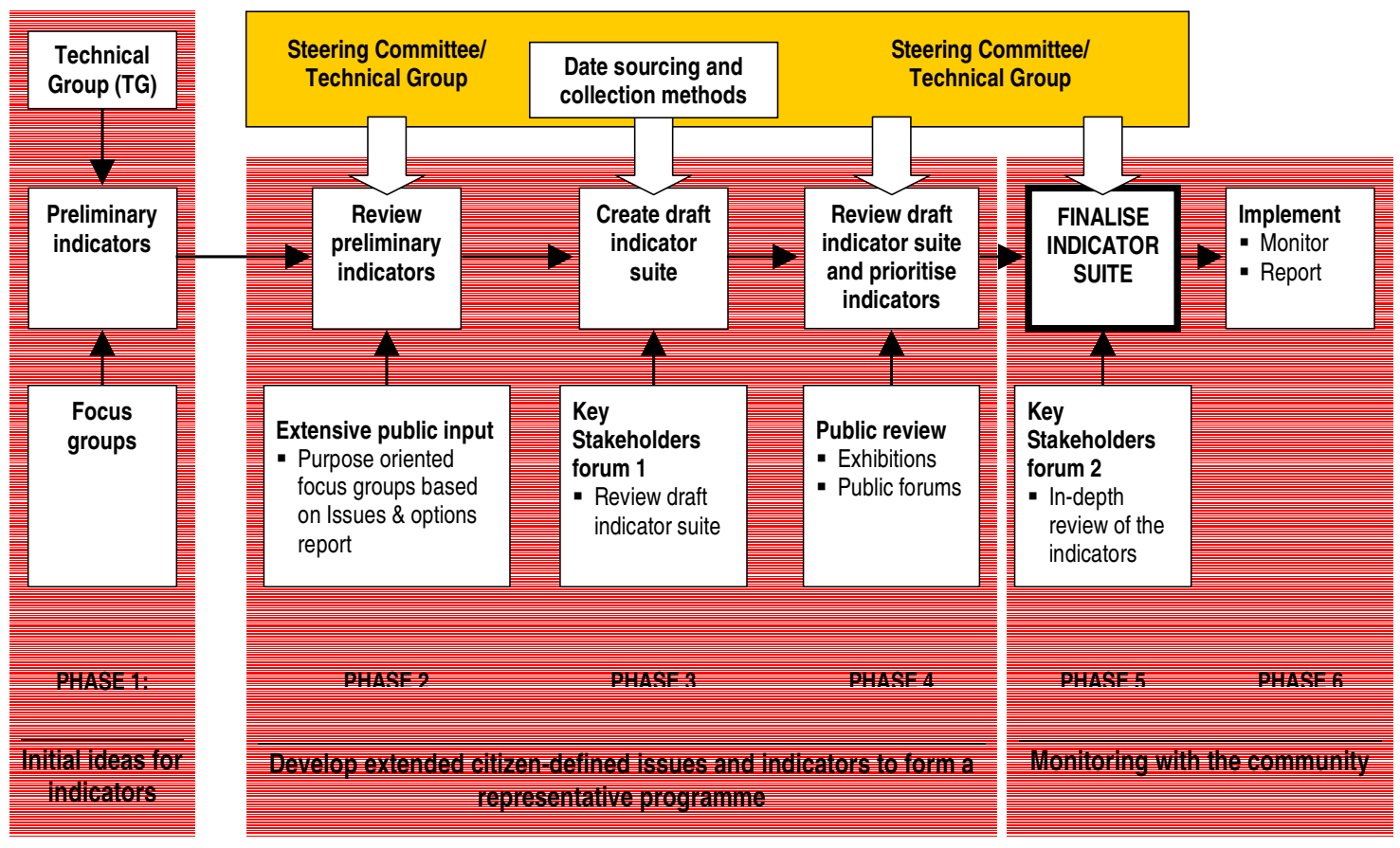

\section{The New Zealand Context}

New Zealand is a lead country in having a legal requirement for community indicators to report progress towards agreed goals at the local and regional level within a whole-of-government strategic planning policy context. For this reason, New Zealand provides a useful setting for a case study. The LGA requires each local authority every six years to consult its community and facilitate identification of desired socio-economic, cultural and environmental 'community outcomes' within its geographical jurisdiction. ${ }^{5}$ The local authority must then identify which outcomes it will assist in promoting and delivering in consultation with other service providers, how it will do so, costs associated with achieving those outcomes, and how it will fund those costs. This information is to be contained in a long term (minimum 10 years) strategic planning document called a Long Term Council Community Plan (henceforth LTCCP), which must be reviewed every six years. Local authorities are also required to regularly monitor and, every three years, report on progress made in the district or region towards achievement of planned community outcomes.

\footnotetext{
4 Adapted from Blair and Murphy-Greene 2006.

5 The two-tier system of local government in New Zealand comprises territorial (district) local authorities and regional councils, both of which are directly elected.
} 
Under the LGA, indicator development is an integral part of the wider process of facilitating identification of community outcomes, monitoring, communicating progress, negotiating central and local government agency responses, and implementing policy changes. A wider underlying objective is to strengthen community governance and enable central and local government to reconnect with communities following two decades of neoliberal policy dominance in New Zealand (Thomas and Memon 2007). Seen from this wider perspective, an ultimate rationale for the indicator development and monitoring and reporting mandate under the LGA is to make peoples' lives better. Indicators are also a vital element of a council's performance management framework for the LTCCP, prescribed in the Act. In this respect, community indicators are also part of the accountability and performance enhancement framework embedded in the LGA for purposes of auditing local authorities by central government. ${ }^{6}$ Arguably, there is tension between competing community governance and public management rationales for inclusion of indicator development and reporting provisions in the Act.

Local authorities need to develop an indicator framework that comprises a suite of indicators for community outcomes and associated monitoring and reporting regimes, developed in collaboration with central government and other stakeholders, and the wider civic society. An indicator framework helps organise potential indicators in such a way that they will provide an accurate picture of progress towards community outcomes. It also provides a context for understanding how indicators relate to each other, how the appropriate data will be collected and reported on, and how the findings will be communicated to all the different stakeholders including the wider community.

\section{Research Findings}

This section presents preliminary findings on emergent local authority responses to their indicator development and monitoring and reporting mandate within a whole-of-government strategic planning framework for community governance, underpinned by the sustainable development purpose of the Act. As reported below, the capability of local governments across New Zealand to implement their mandate effectively varies significantly. For the first generation LTCCPs, most councils have focussed their limited resources on facilitating community outcomes processes and seeking agreement with their communities and service delivery agencies on what the council should be doing to make progress towards achieving desired outcomes. The process has proved to be a steep learning curve for

\footnotetext{
${ }^{6}$ A review of indicators of local authority performance for audit purposes is beyond the scope of this study, notwithstanding the links that exist, from a local authority perspective, between the two levels of monitoring.
} 
most councils as well as other key stakeholders (Leonard and Memon, 2008). There has been considerable interest within the central government sector during the last few years in developing sectoral indicators; the national association of New Zealand local authorities Local Government New Zealand (LGNZ) and Statistics New Zealand have been keen to link these initiatives with meeting the needs of local authorities, however, there has been an absence of co-ordinated and timely guidance from central government to assist development of local government capability. This is reflected, for example, in the slow progress made in developing indicators and monitoring and reporting frameworks to assess achievement of desired community outcomes across local government boundaries.

\subsection{Inter-governmental Collaboration}

Over recent years there has been a growing technical sophistication within the public sector as to what should be monitored and how it should be monitored. There is now a range of indicators available to councils to choose from to monitor progress towards community outcomes. However, as discussed below, achieving inter-governmental collaboration has been a major impediment to developing capability and commitment within the local government sector.

Monitoring and reporting is not new to local government in New Zealand. There is a wealth of experience and past initiatives that can be drawn upon in response to the requirements now imposed under the LGA. All councils were required as part of the earlier 1996 amendment to the Local Government Act 1974 to have in place performance measures to evaluate effectiveness of their activities. Likewise, local authorities are required under the Resource Management Act 1991 to monitor and report on effectiveness of environmental/land-use plans and on planning consent applications.

The most pertinent recent local government-led initiative is the Quality of Life Indicators project commenced in 1999 by the Metropolitan Sector Group of LGNZ (www.bigcities.govt.nz). It aims to develop social, economic and environmental indicators of quality of life in New Zealand's cities. This project has had a notable impact on developing indicator suites for both local and central governments, and also in a general sense in mobilising a whole-of-government approach to indicator development. Its results are well publicised (Metropolitan Sector Group 2007).

Other more recent local government initiatives, such as the Canterbury Region Community Plans Group (Canterbury Region Community Plans Group 2005), the MARCO $^{7}$ group from the Waikato (MARCO 2005 and

\footnotetext{
${ }^{7}$ The MARCO Team (Monitoring and Reporting Community Outcomes) was formed to develop co-ordinated procedures for monitoring progress towards the achievement of community outcomes. The team includes representatives from local authorities, central government and the Waikato District Health Board.
} 
2006), and Future Taranaki (Future Taranaki Facilitation Group 2006) have also had an impact in providing best practice examples for others to learn from. They are all regional groupings, combining regional and territorial (city and district) local authorities, and their experience shows that by sharing resources and expertise significant gains can be made, particularly for smaller councils that would not have had the technical or financial resources to do it alone. Cooperation between regional councils and territorial local authorities is thus seen as important for designing robust community indicator programmes and managing them.

In contrast to the above, the recent Statistics New Zealand-led Linked Indicators Project, which appeared so promising as a whole-of-government initiative, has stalled due to lack of funding and enthusiasm from both local and central governments (Statistics New Zealand 2006). It was designed to serve both central and local government purposes by creating a core set of indicators that is comparable from national to regional to the local level and also uses the same outcome areas. However, the project has been unsuccessful in its latest two funding bids for further development.

During the last seven years some central government departments have also intensified work on developing department-led sectoral indicators and data sets that both they and local government can draw from, with varying degrees of success. Whilst useful, their experience demonstrates that for a whole-of-government approach to work, there needs to be integration and comparability of information and indicators not only horizontally across levels of government, but also vertically. This should occur from national to regional to local levels of government and across the four areas of wellbeing defined in the LGA (social, cultural, environmental and economic).

Encompassing the above local and central government departmental initiatives, the sustainable development movement has to some extent also generated an interest in sustainability indicators in New Zealand. In this context, monitoring is seen as an essential ingredient for the community, local government, central government, the business sector and others to assess if there is movement towards or away from sustainable development goals. The real difficulty has been that there is no single acceptable framework for measuring sustainable development within New Zealand as there is no national sustainable development strategy to measure progress against. There is still disagreement about what sustainable development means in a practical sense within a whole-of-government setting in New Zealand, and thus about how it can be operationalised and measured in relation to community outcomes.

Brown-Santirso (2006) has reviewed recent New Zealand initiatives for sustainability indicators and notes that these provide important learning opportunities for future development. There is an array of different types of approaches in current use. These include the Monitoring Progress towards a Sustainable New Zealand (Statistics New Zealand 2002) and Quality of Life 
in Twelve of New Zealand's Cities 2007 (Metropolitan Sector Group 2007) projects. These initiatives aim to serve policy-making, link the different components of sustainability and address the interfaces between the different elements of wellbeing. There are then the various indicator reports prepared for particular sectors such as the Social Report (Ministry of Social Development 2006) for social wellbeing attributes; indicators for economic wellbeing attributes (Ministry of Economic Development 2005); cultural and heritage indicators (Statistics New Zealand and Ministry for Culture and Heritage 2006); and environmental performance indicators (Ministry for the Environment 2006). In addition, $\mathrm{SANZ}^{8}$ is promoting a suite of indicators that are based on a systems approach that measures the fundamental needs of the environment.

There are also composite measures such as the Genuine Progress Indicator and the Ecological Footprint, and the 'pressure-state-response' approach that has been used particularly for environmental indicators and for State of Environment reporting (Ministry for the Environment 1997). There has been a movement over time from indicators that measure discrete areas (like social, economic and water quality), to a search for indicators that measure the inter-relationships between the different areas.

Most of these efforts relate to specific aspects of sustainable development, and have been developed in isolation without a common framework to link them together. Also, there has been a lack of continuity as several of the initiatives have been one-off projects with no regular follow-up. The lack of a consistent national framework is compelling local authorities to produce information from a combination of local sources, national estimates and modelling. These regional and local statistics are often well researched and meet reporting standards but they are seldom comparable across regions or with national statistics (Brown-Santirso 2006).

Looking specifically at recent central government initiatives, there appears to be a sense of reinventing the wheel with very slow progress forward. While not wanting to be seen to pour cold water on new initiatives, the continual reinvention of indicators for discrete areas does not take New Zealand further ahead towards a whole-of-government sustainable development approach. The recent experience with development of indicators can be seen as a microcosm of how difficult it is to foster the whole-of-government approach within the public sector that was anticipated in the LGA 2002. It appears that some central government departments are building up larger departmental capabilities for indicators and monitoring but despite this, or maybe because of this, there is an apparent lack of commitment to work together.

\footnotetext{
${ }^{8}$ SANZ (Sustainable Aotearoa New Zealand) is a network of practitioners who share a common goal of driving New Zealand towards achieving long -term sustainability. Originally, a number of members were under the umbrella of the Royal Society of New Zealand.
} 
In some cases, progress has been incredibly slow even for indicators in one particular sector. Environmental performance indicators are a case in point, however, the Ministry for the Environment has learned many valuable lessons from its long experience in developing indicators. Some of those lessons are not to have too many indicators, not to be captured by experts, and to seriously consider how data is to be collected over a long period (Johnston and Reid 2006). The lessons are equally relevant to developing community indicator programmes. Although each indicator programme serves a purpose, the raft of central government sector-focused indicator initiatives need to be drawn together under the umbrella of a national sustainable development strategy.

While recent central government driven initiatives have played an important role in developing institutional capability, there is still an area where there is considerable room for improvement. This is Māori indicators: measures based on Māori world views and reflecting Māori wellbeing. A number of observers have acknowledged the lack of a Māori perspective in indicators over the last 15 years, but significant progress does not seem to have been achieved. This is despite the work undertaken by Durie et al. (2002) for Te Puni Kokiri by KCSM Consultancy Solutions and IGCI (the International Global Change Institute) (Jefferies and Kennedy 2005, and Kennedy and Jefferies 2005), as well as more recent work by Durie (2006) which sets out possible frameworks and indicators. Community indicator programmes need to make space for Māori indicators to comply with legislative directions in the LGA.

\subsection{Local Authority Interpretation of the Indicator Development Mandate in the LGA}

A two-pronged study approach was used to examine local authority interpretation of the indicator development mandate in the LGA:

- a scoping analysis of community indicator programmes in 26 selected local authority LTCCPs, representing a range of council types (city, regional and district) and population size;

- scoping case studies of the community indicator programmes of five local authorities.

This review is based on LTCCPs produced in 2006 which are the first generation of fully-fledged LTCCPs required by the LGA to be prepared by all district and regional councils. Though reflecting the limited experience in the local government sector in implementing the Act, the analysis provides an initial assessment of current practice and areas for improvement. 


\section{LTCCP Analysis}

The purpose of this scoping exercise was to get an overview as to how councils have approached and communicated the monitoring and reporting requirements of the LGA through their LTCCPs. It was expected, at the very least, that all the LTCCPs would provide enough detail to comply with the requirements of the LGA. However, the first surprising outcome of the scan was the lack of a complete list of measures in almost half the LTCCPs reviewed. This reflects the fact that a majority of councils are at a relatively early stage of developing community indicator programmes.

Communication of information about councils' indicators and monitoring regimes to the public through their LTCCPs has been patchy. Interviews revealed that some councils have done more extensive work but this is not always described in their LTCCPs. Fifteen councils out of the 26 examined had identified a complete list of indicators or measures. Eleven had yet to do so. Less than half of the councils (10) stated how their indicators had been developed. Most of these described the consultation and collaboration they had with other organisations, but little reference was made to the general public's participation in the indicator development process. Very few LTCCPs included base-line data with the indicators. Only three councils had set targets.

From the scan of the LTCCPs and other council monitoring and reporting documents, it appears that with notable exceptions, mainly amongst larger cities, councils are not involving the general public to any significant extent in deciding how to monitor and report progress towards community outcomes. Deciding on monitoring frameworks and indicators has generally been carried out by the council in consultation and/or collaboration only with other organisations, such as government departments.

\section{Council Case Studies}

Because of the limited amount of information about community indicator programmes contained in the 2006 LTCCPs, it was decided to undertake scoping case studies of the programmes of a selected small group of councils.

Five councils were chosen to explore how they had gone about establishing a monitoring and reporting framework and selection of indicators. They were: Waitaki District Council (population 20,223), Environment Waikato (a regional council with a population of 382,716), Manukau City Council (population 328,968), Environment Southland (a regional council with a population of 90,876), and Christchurch City Council (population 348,435). The councils were chosen in consultation with LGNZ as examples of relatively successful cases of developing community indicator programmes. The five case study councils offered an array of data with which to paint an initial, reasonably informative picture of a community indicator framework. 
With the exception of Environment Southland, our case study councils all have in place robust monitoring and reporting indicators for their community outcomes. The councils have had extensive participation from other agencies in their indicator development, and they all expect that the data will be utilised to inform and in some cases set priorities for the next community outcomes process and the 2009 LTCCP. It is clear from examining their documentation that the councils have in common considerable project planning expertise and skills. Processes have been thoughtfully set out, agreed upon and then implemented in order to meet the legislative requirements in a robust way.

The councils have used slightly different approaches to their indicator development, monitoring and reporting regimes. We have identified four key characteristics from these case studies that have assisted them to meet their obligations. These are outlined below.

Strong Partnerships: The five case study councils have developed strong partnerships for developing their community indicator frameworks. Manukau City Council has a history of partnership development dating back to the 1990s which has continued to the present day. Stakeholders, organisations and the wider public were involved in developing the process, identifying indicators, collecting data and overseeing implementation. Similarly, Waitaki District Council had a process which was very strong on working with stakeholder partners. ${ }^{9}$ The partners not only supplied data, but were also involved in the development of the process to identify indicators. Environment Southland also enjoys strong partnerships: it is behind in the area of identifying indicators and establishing monitoring and data collection systems, but because of its close regional network and shared services forum ${ }^{10}$ the council should have a good cooperative base on which to build.

History of Monitoring: Environment Waikato, Manukau City, and Christchurch City Council had the advantage of already having significant monitoring and reporting frameworks in place prior to the LGA, and had been collecting data for monitoring for a long period of time. Consequently, they have built up considerable expertise and knowledge in monitoring and reporting. Environment Waikato has acknowledged expertise in monitoring: it has produced manuals and guidance material on monitoring and reporting. Under the LGA the council formed MARCO, which is a group of strategic planners who have formulated their core set of indicators for the region. It

\footnotetext{
${ }^{9}$ The 'Waitaki Tomorrow' partners consist of: Alliance Group Pukeuri, Canterbury Regional Council, Department of Conservation, Department of Internal Affairs, Housing NZ Corporation, Land Transport NZ, Ministry of Education, Ministry of Social

Development/WINZ, Otago Regional Council, NZ Police Oamaru, Public Health South, Sport Waitaki, Te Runanga o Moeraki, Waitaki Development Board, and the Waitaki District Council.

${ }^{10}$ The Southland Shared Services Forum is made up of chief executives and councillors. It provides leadership, direction, and oversight of the various joint arrangements, and creates and supports a culture of working together at councillor and chief executive level.
} 
has also explicitly recognised the need to integrate the monitoring required under both the Resource Management Act and the LGA.

Manukau and Christchurch were part of the original six cities in the Quality of Life reporting project mentioned earlier. Like Environment Waikato, they not only have the expertise to develop indicators and systematically collect data, but also the technical capability to analyse the information that they collect.

Regional Co-operation: Environment Waikato, Christchurch City Council and Environment Southland have all worked collaboratively with partners at a local and regional government level. These regional groupings have been able to learn together about the new monitoring requirements, to provide a forum in which central government departments have participated and shared information, and to formulate a core set of regional indicators. A regional grouping thus makes sense in terms of efficiency, sharing expertise and recognising common regional interests.

Community Driven Indicator Development: Manukau City Council has placed a strong emphasis on community involvement in its plans and policy development. This is exemplified by its process for identifying indicators and community outcomes, the way in which different groups are now working on detailed action plans, and how targets have been set by the community and key stakeholders. Manukau City was one of the first councils in New Zealand to develop an indicator programme, The Changing Face of Manukau (Manukau City Council 2004). This process began in the mid 1990s with community input. Preparation of a detailed strategy to guide long-term city development, Tomorrow's Manukau - Manukau Appōpō (Manukau City Council 2006), involved 70 organisations and stakeholder groups.

\section{Discussion}

The analysis of emergent council community indicator frameworks presented in this study is exploratory in view of the relative newness of the LGA. The findings nevertheless pose a number of interesting questions and suggest recommendations for good practice from an institutional perspective.

\subsection{Re-kindling of a Community Indicator Movement in New Zealand?}

With notable exceptions, local authority and community enthusiasm and latitude to develop innovative locally-based community indictor initiatives, evident in other OECD countries, was suppressed in New Zealand until recently by the political dominance of a New Right neo-conservative policy discourse between 1984 and 1999. To a much greater degree than in other OECD states, management of the public sector during this period became 
radically politicised and contestable with a shift to a minimalist state ideology based on the New Public Management policy paradigm. Public sector key performance indicators and performance targets in central and local government agencies focussed on measuring outputs rather than outcomes. In hindsight, corporatist public sector management reforms have failed to deliver value to the public. It is now recognised that central and local government politicians and bureaucrats need to do things differently and look outwards by engaging in dialogue with citizens (Thomas and Memon 2007).

The re-kindling of a community indicator movement in New Zealand, following the election of 'Third Way' centre-left Labour coalition governments since 2000 , has been shaped by a twin political dynamic. First, greater support is now evident on the part of central and local governments for citizen engagement and community strengthening. This in turn reflects recognition by central government of the role of local government as a means of implementing national strategies to promote citizen engagement and community strengthening (Thomas and Memon 2007). Second, there is enhanced interest on the part of central and local governments in the role of community indicators in the context of the sustainable development policy discourse. This interest is shaped by the recognition of complex interrelationships between social, environmental, economic and cultural conditions, and the wellbeing of individuals and communities; a stance advocated for for many years by a number of civil society and iwi (Maori tribal group) organisations without significant political buy-in by central and local governments and corporate leaders.

However, as discussed below, institutional constraints have made it problematic for the nascent community indicator movement to make significant progress.

\subsection{How Appropriate is a Decentralised Model?}

From an institutional perspective, a key research finding of our study is that New Zealand has leant heavily towards a decentralised, locally-based approach to developing community indicator frameworks, with responsibility largely left to individual local authorities. There has been limited specific guidance from central government to assist local government with implementation of the monitoring and reporting obligations placed on local government under the LGA. This is notwithstanding the fact that a few key central government departments have made an effort to develop sectoral indicators relevant to their individual policy mandates.

One may argue that a devolved indicator development strategy within the LGA institutional planning framework based on the principle of subsidiarity is logical and appropriate in a number of respects. A risk of a 'top-down' centrally driven indicator development strategy is that it runs the risk of 
homogenising the community and does not reflect the varied experiences of different communities and localities within society. However, a manifest drawback of the current New Zealand approach is that there is clearly considerable variation across New Zealand in the capability of local governments to develop community indicator frameworks and the results hitherto are therefore patchy. The central government stance is that the LGA is designed so as to provide local authorities with the autonomy to make their own decisions on how they will address the various requirements of the Act. Central government expects councils to make these decisions based on considerations such as local circumstances and recognition of their capacity.

The Linked Indicators Project (Statistics New Zealand 2006) was set up as a joint central and local government initiative to aid the implementation of the Act by developing a core set of indicators useful to both. But some key central government agencies have been reluctant to let Statistics New Zealand take the lead to identify core indicators within a whole-ofgovernment framework, preferring instead to enhance their in-house departmental capacity. The delay of the Linked Indicators Project also reflects lack of sufficient support on the part of the local government sector. This lack of enthusiasm at both the central and local government level demonstrates institutional barriers to collaboration for comparable indicators, both across functional and geographical boundaries, and vertically from central to local government, and negates the whole-ofgovernment stance which underpins the LGA.

\subsection{The Processes for Developing Community Indicator Suites}

A related key research finding is that relatively few local authorities in New Zealand have had significant levels of community involvement in developing their community indicators and monitoring and reporting regimes. There have been cognitive institutional barriers to using the community outcomes processes as a forum for developing community indicators. In New Zealand, there has been an emphasis on involving key stakeholders such as government departments and other holders of information, rather than community organisations and individuals within the wider civil society. With a few exceptions, community involvement has been mainly confined to the process of identifying community outcomes and not in the development of indicators to measure progress towards achieving those outcomes (Leonard and Memon 2008).

While community outcomes visioning exercises routinely incorporate extensive consultation, the process to identify relevant indicators should also involve public consultation on a comparable scale. The participation model for developing a suite of community indicators presented earlier is a useful tool for New Zealand councils to consider when designing their community indicator frameworks. The model suggests going to the wider community on more than one occasion with key stakeholder forums to 
review proposed indicators in-between. In New Zealand, there is a general tendency to put a proposal out for consultation only once, and not to go back to the community to reconsider and deliberate.

\subsection{Technical Attributes of Indicator Monitoring and Reporting Regimes}

We found in our study that assessing technical attributes of indicators developed in LTCCPs at this stage is premature as almost half of the councils in our scan of 26 LTCCPs have not finalised their suite of indicators. Also, councils have not provided much of the background contextual information about their proposed indicators in their LTCCPs, even though some appear to have this information.

Examining the actual indicators that were reported in the LTCCPs shows that the majority of indicators being used are based on either councilgenerated or easily accessible public information. Most indicators are of a quantitative and technical nature rather than being qualitative and community oriented (for example, monitoring community perceptions of health to complement statistical measures).

A small group of local authorities are relatively advanced technically with their indicators. Amongst the five case study councils, it was evident that those that had completed their indicator suites had done so using robust methodologies that involved a number of criteria. The five councils were all similar in that they had established strong working relationships with other organisations. The smallest council, Waitaki District Council, had made very strong key stakeholder links through its community outcomes process, including indicator development and monitoring, and this seems to have been helpful.

Some of the technical weaknesses of indicators and monitoring and reporting regimes identified in the international literature apply to the New Zealand situation, beginning with a lack of plausible and measurable goals and objectives. In New Zealand, many desired community outcomes are intangible and, although well-meaning, remain difficult to measure. A lack of targets and norms is also a weakness in the New Zealand context. (In our scan of 26 LTCCPs, 23 did not have any targets.)

As reported above, central and local governments are now coming together at a technical level to create a menu of indicators that local government can use, for example through the Linked Indicators Project, Quality of Life in Twelve of New Zealand's Cities 2007 (Metropolitan Sector Group 2007), and MARCO group. Guides and manuals have been produced by, for example, Choosing Futures Waikato (MARCO 2005), and central government departments are working with these groups. This work is not yet complete and was not therefore readily applicable to the 2006 LTCCPs. As indicated earlier, there is still no nationally agreed set of indicators for 
sustainability and no national sustainable development strategy. This makes it difficult for territorial local authorities (cities and districts) and regional councils to link community indicators into a wider sustainability framework.

New Zealand's fragmented and strongly decentralised approach to community indicator development stands in marked contrast to the collaborative integrated approach that is currently being adopted in the State of Victoria in Australia (VCIP, 2005 and 2006). The Victorian initiative provides useful pointers for New Zealand to consider in adopting a similar strategic approach to indicator development.

\section{Conclusion}

New Zealand local authorities and central government data providers face significant resourcing issues in meeting the requirements of the LGA. Many local authorities have neither the financial resources nor the skills and expertise needed to develop and maintain an outcomes monitoring programme. Further, some of the central government agencies that are likely to be called upon to provide data for community outcomes monitoring will not be able to handle multiple requests for data at the local level. A more coorientated and integrated approach to monitoring is needed under the collaborative leadership of Statistics New Zealand and the Department of Internal Affairs (DIA).

It seems evident that in order to overcome the barriers to indicator development, Statistics New Zealand should maintain a core set of indicators on behalf of local authorities, with data placed on a central website for ease of access by local authorities. Indicator trend data can be made available through a searchable data-base, as recommended by the Canterbury Region Community Plans Group (2005). Drawing on the experience of monitoring specialists, and on work done in the area to date, a core outcome indicator set should have relevance for all New Zealand local authorities, given the high degree of commonality in community outcomes themes that has become apparent across many local authorities (DIA 2007). Individual councils could complement this shared data by identifying additional local measures specific to their communities and desired community outcomes. This approach would: ensure a co-ordinated approach by data providers; generate cost savings; free-up local authority resources to allow councils to concentrate on provision of data for supplementary local indicators; create the potential for better standardisation of measures to ensure consistent outcomes monitoring across the country; and, facilitate sharing of existing monitoring experience and expertise. 
Acknowledgements: This paper was enabled in part by support from the Public Good Science Fund (PGSF) of the Foundation of Research, Science and Technology (FRST) under contract UOWX0308 for research into the quality of planning and governance under the Resource Management Act (1991) and Local Government Act (2002). Comments on an earlier draft of this paper by our colleagues Dr L. Laurian and Dr. H. Rennie and by the two anonymous referees are gratefully acknowledged.

\section{References}

Bell, S. and Morse, S., 1999. Sustainability indicators: measuring the immeasurable, Earthscan, London.

Besleme, K and Mullin, M 1997, 'Community indicators and healthy communities', National Civic Review, vol. 86, no. 1, pp. 43-52.

Blair, J and Murphy Greene, C 2006, 'Towards a model community indicator programme: drawing experience from the construction of the San Diego-Tijuana CIP', Journal of Humanities and Social Science, vol.1, no. 1, pp. 1-14.

Borrie, N and Memon, A 2005, Long-term council community plans: a scoping survey of local authorities, The International Global Change Institute, University of Waikato, Hamilton.

Borrie, N, Memon, PA, Ericksen, N and Crawford, J 2005, Planning and governance under the LGA: lessons from the RMA experience, International Global Change Institute, University of Waikato, Hamilton.

Brown-Santirso, Martin 2006, 'Sustainable development and the capital approach: conceptual and practical analysis', Working Paper 12, paper presented to the Economic Commission For Europe Conference Of European Statisticians Joint UNECE/OECD/Eurostat Working Group on Statistics for Sustainable Development Second meeting Oslo, 15-16 November 2006, Submitted by Statistics New Zealand.

Canterbury Region Community Plans Group 2005, Draft indicators for monitoring community outcomes; methodology and process for developing indicators, Christchurch City Council, Christchurch.

Department of Internal Affairs, 2006, Analysis of community outcomes from draft LTCCPs 2006-2016, DIA, Wellington.

Durie, Mason 2006, 'Measuring Māori wellbeing', paper presented at the New Zealand Treasury Guest Lecture Series, 1 August 2006, Wellington.

Durie, Mason, Fitzgerald, Eljon, Kingi, Te Kani, McKinley, Sheridan and Stevenson, Brendan 2002, Māori specific outcomes and indicators, Te Puni Kōkiri The Ministry Of Māori Development, Wellington.

Eckerberg, K and Mineur, E 2003, 'The use of local sustainability indicators - case studies in two Swedish municipalities', Local Environment, vol. 8, no. 6, pp. 591 -614 .

Hajer, M J, \& Wagenaar, H (eds) 2003, Deliberative policy analysis: understanding governance in network society, Cambridge University Press.

Healey, Patsy 2006, 'Transforming governance: challenges of institutional adaptation and a new politics of space', European Planning Studies, vol. 14, no. 3, pp. 299320 .

Healey, P, Cars, G, Madanipour, A \& C de Maghalhaes 2002, 'Transfoming governance, institutionalist analysis and institutional capacity', in P Healey, G Cars, A Madanipour \& C de Maghalhaes (eds), Urban governance, institutional capacity and social mileux, Ashgate Publishing, Aldershot. 
Hoernig, H and Seasons, M 2005, 'Understanding indicators' In Phillips, R (ed), Community indicators measuring systems, Ashgate, New York, pp. 3-31.

Innes, Judith 1997, 'Metropolitan development as a complex system: a new approach to sustainability', Working Paper 699, University of California, Berkeley, CA.

Jefferies, R and Kennedy, N 2005, Draft Māori and indigenous environmental performance outcomes and indicators - literature review, KCSM Consultancy Solutions and International Global Change Institute, University of Waikato, Hamilton.

Johnston, Kirsty and Robyn Reid 2006, Lessons learnt from New Zealand's Environmental Performance Indicators (EPI) programmeme, Unpublished paper, Reporting and Review Group, Ministry for the Environment, Wellington.

Kennedy, N and Jefferies, R 2005, Draft kaupapa Māori framework and literature review of key principles, KCSM Consultancy Solutions and International Global Change Institute, University of Waikato, Hamilton.

Kothari, U 2001, 'Power, knowledge and social control in participatory development', in B Cooke \& U Kothari (eds), Participation: the new tyranny?, Zed Books, London.

Leonard, L and Memon, A 2008 forthcoming, Community outcome processes as a forum for community governance, International Global Change Institute, University of Waikato, Hamilton.

Manukau City Council 2006, Tomorrow's Manukau - Manukau Āpōpō, Manukau City Council, Manukau.

Manukau City Council, 2004, The Changing Face of Manukau, Manukau City Council, Manukau.

MARCO 2005, Monitoring and reporting community outcomes. A resource kit for integrated monitoring and reporting, Choosing Futures Waikato, Hamilton.

MARCO 2006, Draft benchmark indicator data report, Choosing Futures Waikato, Hamilton.

Meadows, D H 1998, Indicators and information systems for sustainable development, Sustainability Institute, Hartland Four Corners VT.

Metropolitan Sector Group 2007, Quality of life in twelve of New Zealand's cities 2007, Metropolitan Sector Group.

Ministry for the Environment 2006, Reporting on our environment newsletter, MfE, Wellington.

Ministry for the Environment 1997, The state of New Zealand's environment, MfE, Wellington.

Ministry of Culture and Heritage 2006, Cultural wellbeing and local government report 1: definitions and contexts of cultural wellbeing, MCH, Wellington.

Ministry of Economic Development 2005, Economic development indicators 2005, MED, Wellington.

Ministry of Social Development 2006, Social report 2006 , MSD, Wellington.

Ministry of Social Development 2006a, Social report regional indicators, MSD, Wellington.

Phillips, R (ed) 2005, Community indicators measuring systems, Ashgate, New York.

Rydin, Y \& Falleth, E (eds) 2006, Networks and institutions in natural resource management. Edward Elgar, Cheltenham, UK.

Rydin, Y, Holman, N and E Wolff 2003, 'Local sustainability indicators', Local Environment, vol. 8. no. 6, pp. 581-589. 
Salvaris, M 2000, Community and social indicators. how citizens can measure progress, Institute for Social Research, Swinburne Institute of Technology, Australia.

Statistics New Zealand 2006, Key projects within the regional team in Statistics New Zealand, SNZ, Wellington.

Statistics New Zealand and Ministry for Culture and Heritage 2006, Cultural indicators for New Zealand, SNZ and MCH, Wellington.

Statistics New Zealand, 2002, Monitoring progress towards a sustainable New Zealand, SNZ, Wellington.

Future Taranaki Facilitation Group 2006, Future Taranaki progress report on community outcomes for Taranaki 2006, Taranaki Regional Council.

Thomas Steven \& Ali Memon 2007, 'New Zealand local government at the crossroads? Reflections on the recent local government reforms', Urban Policy and Research, vol. 25, no. 2, June, pp. 1-15.

Victorian Community Indicators Project 2006, Measuring wellbeing, engaging communities, final report, VCIP, Sydney.

Victorian Community Indicators Project 2005, Measuring wellbeing, engaging communities, discussion paper, VCIP, Sydney.

Waring, Marilyn 2006, 'Honouring the experts - participatory data gathering'. key note address to New Zealand Council for Social Services annual conference, Ashburton, October 182006.

Waring, M J 1990, Counting for nothing: what men value and what women are worth, Bridget Williams, Wellington. 